\title{
O funcionamento da educação de tempo integral numa unidade de ensino municipal de Montes Claros-MG: desafios e possibilidades ${ }^{1}$
}

\author{
The functioning of full time education in a unit of municipal education network of Montes Claros- \\ $M G$ : challenges and possibilities \\ Le fonctionnement de l'éducation à plein temps dans une unité d'éducation municipale à Monte \\ Claros-MG: défis et possibilités
}

Dirce Efigênia Brito Lopes ${ }^{2}$ Universidade Estadual de Montes Claros

Regina Célia do Couto ${ }^{3}$ Universidade Federal dos Vales do Jequitinhonha e Mucuri

Resumo: Este trabalho resultou de uma pesquisa sobre o funcionamento da Educação de Tempo Integral (ETI) numa unidade de ensino municipal de Montes Claros-MG, para tal; investigou-se as práticas pedagógicas dos profissionais envolvidos e os impactos das políticas públicas, em especial o Programa Mais Educação junto aos agentes educativos no período 2013-2015. Nessa pesquisa, de natureza quali-quantitativa, utilizou-se de estudo bibliográfico e de campo e da análise de conteúdo para os dados coletados a partir dos questionários e das entrevistas semiestruturadas realizadas com treze envolvidos sendo: dez oficineiros, um gestor e dois coordenadores da ETI. Após análise, os dados foram organizados em seis categorias: funcionamento e infraestrutura; interlocução escolacomunidade; conhecimento de ETI e educação integral (EI) e suas bases legais; desafios; impactos e práticas pedagógicas. A pesquisa tem relevância por apresentar indicadores sobre a ETI que a secretaria municipal de educação poderá utilizar posteriormente em busca da melhoria da qualidade da educação.

Palavras-chave: Educação Integral. Educação de Tempo Integral. Funcionamento Escolar. Escola/Comunidade.

Abstract: This work was the result of research on the functioning of full-time education (FTE) in a municipal teaching unit in Montes Claros-MG. For such, the pedagogical practices of the professionals involved and the impacts of public policies were investigated, in particular the More Education Program with educational agents in the 2013-2015 period. In this qualitative and quantitative research, we used a bibliographic and field study and content analysis for the data collected from the questionnaires and semi-structured interviews conducted with thirteen involved: ten workshoppers, one manager and two

\footnotetext{
1 Esse texto foi inicialmente apresentado como dissertação no Mestrado realizado no Programa de PósGraduação em Educação da Universidade Federal dos Vales do Jequitinhonha e Mucuri (UFVJM).

${ }^{2}$ Mestre em Educação pela Universidade Federal dos Vales do Jequitinhonha e Mucuri-UFVJM. Professora de Didática e Metodologia Científica da Universidade Estadual de Montes Claros-Unimontes nos cursos de graduação e Pós-graduação. Supervisora Pedagógica de Ensino da Secretaria Municipal de Educação em Montes Claros-MG. E-mail: dirceuabifnmg@gmail.com. ORCID: https://orcid.org/0000-0001-6980-9658. Lattes: http://lattes.cnpq.br/3366807672850186.

${ }^{3}$ Doutora em Educação. Professora da Universidade Federal dos Vales de Jequitinhonha e Mucuri- UFVJM.

E-mail: rccouto@hotmail.com. ORCID: https://orcid.org/0000-0001-5747-1418. Lattes: 
coordinators of the FTE. After analysis, the data were organized into six categories: operation and infrastructure; school-community dialogue; knowledge of FTE and integral education (EI) and its legal basis; challenges; impacts and pedagogical practices. The research has relevance for presenting indicators on the FTE that the municipal department of education can use later in search of improving the quality of education.

Key words: Integral education. Full Time Education. School functioning. School / Community.

Resumé: Ce travail est le résultat d'une recherche sur le fonctionnement de l'enseignement à temps plein (ETP) dans une unité d'enseignement municipale à Montes Claros-MG. Pour cela, les pratiques pédagogiques des professionnels impliqués et les impacts des politiques publiques ont été examinés, en particulier le programme Plus d'Éducation avec des agents de formation pour la période 2013-2015. Dans cette recherche qualitative et quantitative, nous avons utilisé une étude bibliographique et sur le terrain et une analyse de contenu pour les données recueillies à partir des questionnaires et des entretiens semi-structurés menés avec treize participants: dix workshopper, un responsable et deux coordinateurs de la FTE. Après analyse, les données ont été organisées en six catégories: exploitation et infrastructure; dialogue école-communauté; connaissance des ETP et de l'éducation intégrale (IE) et de ses fondements juridiques; défis; impacts et pratiques pédagogiques. La recherche est pertinente pour la présentation d'indicateurs sur les ETP que le département municipal de l'éducation peut utiliser plus tard pour améliorer la qualité de l'éducation.

Mots clés: Éducation à plein temps. Fonctionnement de l'école. Ecole / Communauté.

\section{Introdução}

A Educação de Tempo Integral (ETI) ao ser implantada, de modo ampliado, no sistema educacional do município de Montes Claros no ano de 2010 despertou interesse visto que as inovações geraram consequências e impactos, principalmente para quem estava na linha de frente das escolas, os gestores. Questões emergiram durante a implantação do Programa Mais Educação4, essas se voltavam para aspectos conceituais; infraestrutura, qualificação de pessoal; resistência de professores e pais; equipamentos disponíveis.

Nessa pesquisa nos estudos bibliográficos analisaram-se conceitos de ETI e Educação Integral (EI) baseadas em autores como Moll, Cavaliere, Gadotti e Coelho. No ano de 2010, a implantação do Programa Mais Educação/Educação de Tempo Integral em cinco unidades municipais de ensino que apresentavam baixo Índice de Desenvolvimento da Educação

\footnotetext{
${ }^{4}$ Programa Mais Educação: Estratégia do Ministério da Educação para induzir a ampliação da jornada escolar e organização curricular na perspectiva da Educação Integral escolar, instituído pela Portaria Interministerial n. ${ }^{\circ}$ 17/2007 e regulamentado pelo Decreto n. ${ }^{\circ}$ 7.083/90 (Manual de Operacional de Educação Integral- MEC, 2012).
} 
Básica (IDEB) e eram classificadas como escola de grande porte ${ }^{5}$. Assim, selecionou-se a Escola Municipal Mestra Fininha em Montes Claros-MG.

Essa pesquisa teve como objetivo geral compreender os impactos da implantação e o funcionamento da Educação de Tempo Integral na citada unidade de ensino. Os participantes foram selecionados pelo fato de trabalharem com as oficinas da ETI, sendo eles o gestor da escola, dois coordenadores, um da Escola Municipal Mestra Fininha (EMMF) e outro da Secretaria Municipal de Educação (SME) e dez oficineiros (cinco estagiários e cinco professores). O período investigado situou-se entre os anos de 2013 a 2015.

Optou-se por desenvolver uma pesquisa de natureza quali-quantitativa, na qual se realizaram revisões bibliográficas e análise documental, bem como o estudo de campo para observar o desenvolvimento das práticas pedagógicas na Educação de Tempo Integral. Conforme Souza (2012, p. 63) “a preocupação da pesquisa qualitativa não é provar alguma coisa, é antes analisar criticamente os problemas buscando, dessa forma, uma compreensão contextualizada da realidade".

Como instrumentos para coletas de dados foram agrupados o questionário (composto de vinte e seis questões, sendo dez abertas e dezesseis fechadas) e a entrevista semiestruturada (composta de nove questões). Realizou-se a caracterização da unidade de ensino, os dados coletados dos questionários foram utilizados para compor o perfil dos pesquisados e os das entrevistas foram organizados em categorias: funcionamento e infraestrutura; interlocução escola X comunidade; conhecimento de ETI e EI e de suas bases legais; práticas pedagógicas; impactos e desafios e possibilidades.

Utilizou-se a técnica da análise de conteúdos para interpretá-los. Bardin (2010, p.127) ressalta que "o analista, tendo à sua disposição os resultados significativos e fiéis, pode então propor inferências e adiantar interpretações a propósito dos objetivos previstos, ou que digam respeito a outras descobertas inesperadas".

Esse artigo está estruturado em seções em cujos tópicos se aborda os principais aspectos da pesquisa teórica assim como os das categorias acima elencadas.

\section{A construção do conceito de Educação Integral e Educação de Tempo Integral}

A Educação Integral, no decorrer da história, apresentou-se como possibilidade para o desenvolvimento da formação integral do cidadão e a Educação de Tempo Integral

\footnotetext{
${ }^{5}$ Denominação dada às escolas municipais de Montes Claros cujo número de matrículas é de 500 ou mais alunos.
} 
seria a ampliação da jornada que o aluno passaria na escola, com atividades voltadas para diversas áreas do conhecimento.

Restaurar o equilíbrio entre a educação recebida diretamente das escolas e a não formal, recebida pela vida, era a busca incessante de Dewey. Ele acreditava que a realização de qualquer ação para educar precisava de organização e direção e que a escola deveria oferecer um ambiente em que as crianças pudessem desvendar segredos e participar deles. Nessa concepção a necessidade da Educação Integral é que a escola ofereça situações de interação e construção de conhecimento para que possam ser utilizados em prol da própria vida e em busca da felicidade do cidadão. Dewey (1979) afirma que crianças vão à escola em busca de aprender integralmente.

Na concepção de Teixeira (1999) a escola deveria suprir as deficiências das demais instituições inclusive da educação familiar. Por isso, previu construções de Escolas Parque, que além de ensinar, abrigavam crianças órfãs ou abandonadas, apesar de não ter o objetivo de ser internato. Ele acreditava que era a escola que deveria se adequar às crianças e não o contrário. Além de criticar o tempo reduzido das jornadas nas escolas brasileiras, defendia a ampliação dos turnos e uma reforma no sentido de uma educação integral, voltada para os aspectos cognitivo, social e cultural.

Teixeira entendia que a educação deveria ocorrer em consonância com a vida e tudo que ela oferece. Por isso, não poderia se isolar da sociedade. Para tanto, as atividades, os dias letivos e os anos de duração do ensino primário deveriam ser ampliados. Só dessa poderia se garantir a formação de um aluno cidadão, preparado para vida. A escola deveria oferecer o ensino de artes, atividades físicas e culturais e o aprendizado de uma profissão. Em seu discurso a favor da educação, dizia:

[...] Referi-me a movimento de emancipação educativa - e não o fiz sem intenção. Não me parece que estejamos aqui para discutir como "disciplinar" a educação nacional, mas como "promovê-la", como desencadear as forças necessárias para levar a efeito um movimento, a mobilização geral de esforços e recursos para resolver o problema do direito dos direitos do brasileiro: o de se educar para ser cidadão, para ganhar a vida e para viver com decência e dignidade (TEIXEIRA, 1999, p. 166).

O que se percebe aqui é a preocupação de Anísio Teixeira em deixar clara sua intenção com relação ao movimento de emancipação educativa, movimento este que teve como objetivo importante a promoção da educação e a valorização do cidadão brasileiro.

Paro (2009, p.17) também apresenta uma concepção de Educação Integral que realizaria efetivamente a formação do sujeito autônomo, capaz de se apropriar da cultura de modo a ser "autor de sua humanidade". Reafirma que o conceito de humano não se restringe 
ao seu corpo, mas sim àquilo que o homem faz e que produz, e é assim que faz história e produz sua própria vida.

Autores diferentes têm visões semelhantes sobre a EI. Moraes (2009) buscou na corrente anarquista, século XIX, a concepção de EI, na qual apresentava as relações trabalho-educação, que deve ser capaz de abranger a totalidade do ser humano e de suas expressões, relações, produções e práticas. Cavaliere (2009) analisando Paro e Moraes, afirmou que os autores apontam a EI como via de superação da alienação, possibilidade para a formação da autonomia, da condição emancipada, sem desconsiderar todos os limites e incertezas que a expressão ainda carrega.

\section{Educação em tempo integral no sistema público de ensino do município de Montes Claros/MG: da política à prática cotidiana}

\subsection{A unidade de ensino}

As unidades de ensino municipais em Montes Claros são classificadas em pequeno porte quando contam com até 300 alunos; médio porte, de 300 a 500 e grande porte, de 500 alunos acima. Em 2010 implantou-se a ETI em todas as 26 escolas.

A Escola Municipal Mestra Fininha, objeto desta pesquisa, foi selecionada de forma aleatória, e faz parte do grupo das 05 escolas classificadas como de grande porte. Tem um quadro composto por setenta e seis funcionários, entre efetivos e contratados atuantes no ensino regular e no ETI.

Está situada em um bairro periférico de Montes Claros, denominado Conjunto Ciro dos Anjos, em que as crianças estão submetidas a alto risco de periculosidade (tráfico, prostituição, abuso sexual) e, portanto, em situação de risco e vulnerabilidade social além de apresentar IDEB 5.0, em 2013, abaixo da meta prevista que era de 6.0, conforme dados do Instituto Nacional de Estudos e Pesquisas Anísio Teixeira (INEP, 2013).

Até o ano de 2015, a ETI funcionava com doze oficineiros/professores (Matemática, Língua Portuguesa e Letramento), três oficineiros/estagiários (Educação Física, Percussão e Artes), uma coordenadora responsável e uma supervisora pedagógica, além de dois serventes de zeladoria e duas cantineiras. Todos distribuídos entre os turnos matutino e vespertino.

No relatório final elaborado pela EMMF de 2013-2014 do Programa Educação de Tempo Integral, enviado para análise na SME, consta que o objetivo geral é 'atender à comunidade' que vive em alto nível de vulnerabilidade social e que encontra na Escola o único 
meio de lazer, entretenimento, socialização, aquisição de conhecimento e enriquecimento cultural' e ainda para adquirir hábitos de boa convivência, socialização formação para o trabalho e esportes e o enfrentamento das drogas (RELATÓRIO FINAL, 2013-2014, p.3).

Considera-se que a escola apresenta objetivos que desconsideram a comunidade em que a criança está inserida, importante e significativa para ela, principalmente quando aponta que a escola irá educar para que a criança seja capaz de cumprir as regras dominantes impostas pela sociedade. Para a unidade de ensino o problema do envolvimento com droga, por exemplo, está presente na comunidade por ser menos favorecida e que, portanto, os educadores têm a missão de "moldar" os alunos para ficarem longe do crime.

Moll (2009) e Cavaliere (2009) argumentam que a ETI é uma política pública que propõe o resgate das crianças, fazendo com que elas permaneçam mais tempo na escola realizando atividades que favoreçam seu desenvolvimento integral. Para elas, a ampliação da jornada escolar para turno integral tem dado bons resultados. $\mathrm{O}$ atendimento em tempo integral, oportunizando orientação no cumprimento dos deveres escolares, prática de esporte, desenvolvimento de atividades artísticas e alimentação adequada, no mínimo em duas refeições, é um avanço significativo para diminuir as desigualdades sociais e ampliar democraticamente as oportunidades de aprendizagem (BRASIL, 2001).

\subsection{Os participantes da pesquisa: o que fazem, o que pensam}

Em um universo de trinta e um professores que compõe o quadro da EMMF, quinze do $1^{\circ}$ ao $5^{\circ}$ ano e dezesseis do $6^{\circ}$ ao $9^{\circ}$ ano, seis participam da ETI, mas, para a amostra da pesquisa, cinco professores foram selecionados, todos pertencentes aos anos finais do Ensino Fundamental. Por serem poucos professores, a intenção era que os seis participassem da pesquisa, porém um não compareceu.

Dois professores são graduados em Letras/Português, dois em Matemática e um em Pedagogia. Quando interrogados sobre o porquê buscaram trabalhar na ETI, eles informaram que tinham expectativas na melhoria de resultados dos alunos, queriam ter mais oportunidade monetária, adquirir novas experiências, por ser um desafio profissional e por acreditarem ter perfil e sensibilidade para trabalhar com crianças em situação de risco. $\mathrm{O}$ grupo de 05 (cinco) oficineiros era composto por professores e estagiários. As oficinas envolviam as disciplinas de Português e Matemática além de atividades de arte, cultura, lazer e esporte como judô, fanfarra, capoeira, futebol entre outros.

Os professores afirmaram que sentem falta de cursos de capacitação para aprimorarem a prática pedagógica. Os oficineiros/estagiários foram unânimes em afirmar 
que a SME oferece formação na escola, mas não explicitam como ela acontece. Nesse aspecto notou-se incoerência, pois a SME não capacitou seus funcionários e nem as escolas para a implantação da ETI, e ainda continua não capacitando este pessoal. Isso posto, entende-se que a formação continuada permite "aos professores apropriar-se de seus processos de formação e dar-lhes um sentido no quadro de suas histórias de vida” (NÓVOA, 1995, p 25).

Essa formação poderá permitir aos profissionais envolvidos maior comprometimento maior e postura diferenciada diante das atividades propostas para a ETI e melhor relacionamento com os alunos. Observou-se uma insatisfação do professor no fato de dispor de suas finanças para realização das atividades, o que não vem ao encontro do que é proposto nas Diretrizes Operacionais/2016 da ETI. Nessas Diretrizes, consta que "para manutenção do Tempo Integral, as unidades de ensino contam com recursos do Programa Mais Educação, destinados ao ressarcimento das despesas dos oficineiros; a aquisição de materiais pedagógicos e de consumo [ ...]” (MONTES CLAROS, SME, 2016, p.2).

Ao confrontar as respostas dadas pelos oficineiros e professores, constatou-se a presença das mesmas dificuldades para o desenvolvimento do trabalho. As respostas estão carregadas de significados e de ideologias devido a cultura dos envolvidos, assim como a uma real dificuldade para a execução do trabalho pedagógico na escola. Pontos como espaço, materiais pedagógicos, não envolvimento dos pais, entre outros destacados pelos professores/oficineiros/estagiários são importantes para a ETI, e eles podem afetar a qualidade educacional.

Os materiais (da fanfarra, de artes e música) estão sucateados, são guardados na biblioteca também, e o espaço ficou menor ainda. Os oficineiros acusaram a falta de materiais, que, às vezes eles mesmos têm que produzir a partir de sucatas o material de uso, quando não tem que adquirir com recursos próprios.

Uma realidade, como afirma Maurício (2009), é que, se há uma necessidade de tempo há também a necessidade de espaço. Para ela, é intrínseco à proposta de Escola de Tempo Integral instalações adequadas, refeitório compatível com a demanda, equipamentos em sala de multimeios, internet, acrescentando ainda que é primordial também ter espaço suficiente para reuniões de aluno para prepararem campeonatos, comemorações e conselhos. A citada autora argumenta que "educação não é despesa, é investimento, porque traz retorno social e econômico” (MAURÍCIO, 2009, p.55). Na EMMF o espaço e os materiais ainda não são adequados para que aconteça a ETI, as salas são improvisadas, alunos desenvolvem atividades inapropriadas, por exemplo, trabalham no hall de entrada e até debaixo de árvores.

Um profissional em destaque na ETI que participou dessa pesquisa foram as duas coordenadoras pedagógicas. Mesmo tendo demonstrando interesses opostos, as coordenadoras sentem-se satisfeitas com a ETI e são unânimes em afirmar ser uma 
oportunidade de melhoria na vida das crianças. Nos depoimentos se evidenciou a crença no papel redentor da educação e na escola como único local onde a aprendizagem de fato ocorre. É a escola se apresentando como locus privilegiado e coerente com a lógica da racionalidade técnica, "apoia-se na ideia de acúmulo de conhecimentos ditos teóricos para aplicação ao domínio da prática” (MIZUKAMI et al, 2003, p.13).

Ao serem indagados sobre a capacitação dos envolvidos na ETI, que está prevista também nas diretrizes operacionais das escolas de tempo integral, afirmaram que ocorre sim, mas infelizmente não atende a todos os envolvidos. É notória a divergência existente nos relatos dos coordenadores. Talvez por serem sujeitos diretamente ligados à administração e por terem sido indicadas para os cargos, prática ainda comum nas prefeituras, infelizmente. As divergências demonstraram a fragilidade e pouca sintonia do trabalho, o que pode afetar o desenvolvimento da ETI.

A outra profissional a compor o quadro dos participantes foi a gestora da EMMF. Ela é pedagoga com mestrado em educação e supervisora pedagógica de ensino da SME, atualmente na direção da EMMF. Ao ser indagada sobre quais conhecimentos detinha sobre a EI e ETI, ela informou que não tinha nenhum conhecimento da ETI antes do atual trabalho. Ressalta-se que uma das atribuições do gestor, segundo as Diretrizes Operacionais das Escolas de Tempo Integral/2016, é "Conhecer e submeter-se às Diretrizes Operacionais do Programa de Tempo Integral/2016 (SME) e legislações afins (pdeinterativo.mec.gov.br)" (MONTES CLAROS, 2016, p.10).

Quando o próprio gestor não apresenta segurança no programa que está sendo executado na unidade de ensino que dirige, a comunidade terá mais dificuldade em envolverse. A gestora afirmou que iniciou as atividades com ETI "somente com muita vontade de acertar, mas, no decorrer do trabalho, foi se envolvendo e participando de discussões, realizando leituras e tentando entender um pouco mais sobre a ETI”. Ela se esforça para cumprir as determinações da SME e assim realizar bem o seu trabalho.

O desconhecimento sobre a ETI por parte dos envolvidos, para autores como Moll (2009) e Cavaliere (2009), chega a ser inadmissível, não há como aceitar que pessoas que lidam com um determinado programa não o conheçam a fundo. E isso ficou explicito no relato da gestora. É necessário conhecer o que se propôs trabalhar para alcançar os objetivos propostos e fazer com que todos envolvam com compromisso e responsabilidade nas ações.

Nota-se uma centralização das decisões na própria SME, mas também uma passividade da gestora da unidade de ensino. Enquanto a ETI propõe um trabalho voltado para o desenvolvimento da autonomia dos alunos e desenvolvimento de criticidade a partir da interação, percebeu-se que a própria gestora está presa às determinações da SME. 
Conforme constam nas Diretrizes Operacionais para as Escolas de Tempo Integral da SME, são atribuições do diretor das Unidades de Ensino: "Estabelecer parceiras com empresas, instituições de ensino, ONGs, associações de moradores, igrejas, clubes sociais e espaços culturais que se encontram no entorno da escola para a realização das atividades" (MONTES CLAROS, 2016, p.10).

Essas parcerias estão previstas na Portaria Interministerial n. ${ }^{\circ} 17$, de 2007, que também ampliou para outros ministérios a corresponsabilidade pelo desenvolvimento das ações da educação integral.

\subsection{Funcionamento e infraestrutura}

$\mathrm{Na}$ categoria funcionamento e infraestrutura, não foi diferente de outras pesquisas desenvolvidas sobre ETI, constatou-se que ainda é o maior desafio na execução das ações. Os espaços físicos não foram adequados para o recebimento de crianças em horário duplicado na unidade de ensino. Isso acabou gerando também um desconforto entre os professores regulares das turmas, os estagiários e os docentes participantes do programa. A EMMF não dispunha de salas adequadas para realização das atividades.

O funcionamento das atividades da ETI, segundo relatos dos sujeitos, segue uma padronização em todas as escolas do sistema municipal de ensino. Os alunos, ao adentrarem nas escolas, desenvolvem essas atividades buscando maior interação tanto com colegas quanto com os pares na sociedade em que vivem. Os oficineiros/estagiários e professores relatam o prazer que os alunos sentem em verem a execução das atividades sendo valorizadas por todos. Acredita-se que, mesmo enaltecendo o prazer dos alunos na realização das atividades, vale ressaltar que a padronização proposta não leva em conta a realidade da comunidade onde a unidade de ensino está inserida, suas características e as dos alunos. São situações, desejos e oportunidades diferenciados. Portanto, a proposta da ETI para as escolas também deveria ser diferenciada e adequada às realidades das comunidades. É nesse aspecto que a ETI deve se pautar, não se pode fazer tudo igual com comunidades tão diferentes.

Com relação a infraestrutura e equipamentos, afirmaram:

OF3 [...] A escola não tem estrutura para recebimento do tempo integral, um dos desafios da unidade nossa seria a estrutura, verbas, porque falta material, e espaço para comportar o número de alunos naquele horário. P3 [...] O espaço físico, de repente a escola não estava adaptada para receber esses professores que vieram para lecionar essas disciplinas, em tempo integral, $[\ldots]$. 
Ao analisar essas respostas, percebemos entraves para a realização adequada das atividades é a falta de espaço físico, de infraestrutura adequada e como citada, de recursos materiais para dar suporte às atividades.

As considerações acima remetem a Gadotti (2009, p.31), quando afirma que "um dos importantes desafios do sistema público de ensino é fazer chegar às populações mais pobres os benefícios das novas tecnologias e ampliar os espaços de formação para além da escola”. Não se pode oferecer somente educação, tem-se que ofertá-la com qualidade.

A busca pela qualidade no espaço educacional requer revisão de posturas e a necessidade de se repensar qual sujeito se quer formar, para qual educação e para qual sociedade. Para tanto, entendemos que a ETI de qualidade pode acontecer em todos os lugares, não se limita à regulação e papéis oficiais.

\subsection{Interlocução Escola-Comunidade}

As falas dos pesquisados remeteu-nos a um modelo de relação escola/comunidade mais tradicional, em que a escola espera que a comunidade venha até ela e não aproveita os espaços que a própria detém. O que se observa é que a relação escola/comunidade está longe do que propõe a EI. Não são firmadas as parcerias fora da escola, somente convida a comunidade para visitar a escola em eventos festivos e que sempre tenha um atrativo, de preferência, lanche. A comunidade, aparentemente, é carente, tanto de recursos como de conhecimento de seus direitos por uma educação de qualidade.

C1 - Nós temos uma convivência muito boa, e eu consegui isso assim: no início, nós chamávamos para as reuniões e eles nunca vinham. Aí eu comecei fazendo as oficinas para eles participarem e estarem juntos, aí na hora que eles vinham, juntavam-se para a oficina, nós sempre servíamos um lanche, com isso conseguimos ter uma relação boa com a comunidade, mas eu posso falar com você que o máximo que eu tenho é $60 \%$ da comunidade presente na escola nesse programa, mas o que eu consegui até hoje foi assim, para eles virem assistir às oficinas. Como temos a banda, sempre que tem uma reunião, colocamos a banda para tocar, aí os pais estão presente (sic) e chamam os outros também. Mas é complicado, os filhos são muito largados, são muito sozinhos. […] Tem menino que não tem assistência de nada, de ninguém, então é complicado essa relação com a comunidade.

OF $5[\ldots]$ A escola abre esse espaço para que a comunidade perceba que ela não está escondida, que os alunos são capazes.

A interlocução Escola-Comunidade é uma estratégia que todos os envolvidos na ETI devem almejar. Os espaços na comunidade, como praças, clubes, ONGs, são indispensáveis para se entender que a educação acontece também fora da escola e que os alunos necessitam 
sentir que podem aproveitar e transformar a comunidade em que vivem. Nas falas dos depoentes ficou implícito que, pelo fato da unidade de ensino se situar em uma comunidade de alto risco, é mais seguro e, para eles, portanto melhor permanecer dentro dela desenvolvendo as atividades.

Nas reflexões propostas, percebe-se que ainda consideram a escola um espaço quase único de construção de conhecimento. A escola deve ser espaço-tempo de formação do cidadão, mas não é o único. Isso reforça a necessidade da escola sair dos seus muros e socializar o saber produzido, dessa forma, os pais e a comunidade poderão auxiliar o trabalho pedagógico e não simplesmente serem submissos às decisões tomadas pela escola em prol do seu filho. Parece que nem os educadores da ETI ainda perceberam essa importância.

\subsection{Conhecimento de educação integral: o que dizem os participantes}

Nessa categoria, os conceitos dados pelos entrevistados demonstraram que o conhecimento sobre ETI e EI é confuso e limitado. Porém, mesmo partindo do conhecimento de senso comum, eles acreditam que haja diferença entre os conceitos, porém não os apresentam, somente tentam explicar sem consistência teórica. Trabalham com a ETI, mas não sabem dizer quais são os pressupostos e diretrizes que a embasam.

Entretanto, as diferenças entre os conceitos existem e Gadotti (2009, p.29) demonstra que "Educação Integral é uma concepção que não se confunde com o horário integral, o tempo integral ou jornada integral”. Sendo assim, a EI não pode ser confundida com a ETI, que depende muito da participação dos pais e da comunidade em geral, pois ela será desenvolvida em espaços formais, não formais e informais.

Enquanto temos os envolvidos na pesquisa ressaltando que um conceito não se diferencia do outro, Moll (2009, p.18) afirma que "de nada adiantará esticar a corda do tempo: ela não redimensionará, obrigatoriamente, esse espaço”. E é nesse contexto que a educação integral emerge como uma perspectiva capaz de ressignificar os tempos e os espaços escolares. Percebeu-se ainda que, mesmo os sujeitos envolvidos na pesquisa que se posicionaram alegando haver diferença entre ETI e EI, não o fizeram com embasamento teórico e nem com convicção, pois EI não pode ser confundida com escolarização.

$\mathrm{O}$ desconhecimento dos envolvidos sobre ETI pode trazer consequências para o alcance dos objetivos na realização das atividades; para o envolvimento na busca de parcerias adequadas; para o desenvolvimento integral e não compartimentado das crianças. Saber conceituar e reconhecer os documentos que embasam as ações da ETI pode garantir mais segurança no desenvolvimento das ações da ETI. É conflituoso um profissional lidar com 
ações das quais desconhecem as origens, o embasamento teórico e legal, os possíveis resultados, o que torna mais difícil legitimar intenções.

\subsection{Práticas pedagógicas na educação em tempo integral}

Essa categoria foi necessária para que se pudesse investigar a influência das práticas pedagógicas no alcance da aprendizagem dos alunos que participam da ETI. Percebeu-se que tanto os professores quanto os oficineiros demonstram dificuldades em relatar práticas consistentes com a EI. Eles falam de maneira genérica que trabalham com aulas diferenciadas e atividades lúdicas, mas não apresentam nenhuma outra situação que mereça destaque no desenvolvimento integral das crianças.

Gadotti (2009) ressalta a importância de se ter perfil para o desenvolvimento das ações na ETI. Não basta somente a vontade e a presença do aluno no tempo integral, necessita ser também um professor de tempo integral. Gadotti (2009) descreve que precisa ser "profissional do sentido", aquele que contribui para significar os projetos de vida.

Antunes e Padilha (2010) destacam que, numa concepção integral de educação, o trabalho do educador ganha um novo sentido, que está diretamente ligado à participação dos pais e da comunidade. Nesse momento, é válida a crítica feita às práticas pedagógicas dos entrevistados, que em momento algum destacam atividades que envolvam também os pais e a comunidade como aquelas que irão ajudá-los na consecução dos objetivos da ETI.

\subsection{Impactos da educação em tempo integral na escola pesquisada}

Um dos objetivos desta pesquisa foi analisar os impactos do funcionamento da ETI na EMMF. Pelas falas dos sujeitos, não se pôde perceber grandes impactos na vida da comunidade, alunos e professores. Os pesquisados conhecem pouco e/ou superficialmente a proposta, alegam que a infraestrutura e o material não são adequados, acusam não terem tido ou que tiveram pouca capacitação para trabalhar, que a relação com a comunidade é superficial, que não foram realizadas parcerias para incrementar a educação, que não existe verba para o desenvolvimento das atividades. Caso estes desafios não sejam enfrentados, os impactos podem ser negativos e os objetivos da EI não serão atingidos. A falta de recursos para custear as despesas da impediu, por exemplo, que muitos projetos fossem desenvolvidos, excursões fossem feitas e trabalhos diferenciados fossem realizados.

Ocorreu também a diminuição das oficinas por escassez de recursos financeiros, por mais que tivessem sido escolhidas pela escola e alunos para acontecerem. No que tange a um 
dos objetivos da ETI que é amenizar a situação de risco e vulnerabilidade, retirando as crianças das ruas, citado por eles, percebeu-se que o que foi apresentado pelos entrevistados não tinha força suficiente para modificar tal situação. É evidente que as verbas são importantes, mas, além delas, o que impactou mais a comunidade com a implantação da ETI na EMMF? Somente um professor descreveu que as crianças se envolvem com as atividades mais prazerosas e demonstraram uma melhora significativa na aprendizagem e nos relacionamentos interpessoais. Porém, os envolvidos não consideram, em seus relatos, esses fatos como impactantes na comunidade escolar.

Se a EMMF utilizasse mais os espaços disponíveis na comunidade, como quadras e praças, teria condições palpáveis de descrever os impactos percebidos também na comunidade e nos alunos. Gadotti (2009, p. 31$)$ ressalta:

A escola pública precisa ser integral, integrada e integradora. Integrar ao projeto Ecopolítico e Pedagógico da escola as igrejas, as quadras de esporte, os clubes, as academias de dança, de capoeira e de ginástica, os telecentros, parques, praças, museus, cinemas etc., além de universidades, centros de estudos, Ong's e movimentos sociais; enfim, integrar o bairro e toda a comunidade.

Aventa-se que alguns dos impactos que poderiam ser percebidos na comunidade a partir do desenvolvimento das ações da ETI seria decorrente da utilização dos espaços coletivos na comunidade para desenvolverem atividades que pudessem empoderar as crianças e adolescentes e ao mesmo tempo potencializar o sentimento de pertencimento para, desse modo, amenizar as situações de risco e vulnerabilidade, valorizando o cidadão no seu sentido amplo e a sensação real de fazer parte do processo de desenvolvimento cultural, social e econômico da cidade.

\subsection{Desafios e possibilidades para a educação em tempo integral na Escola Municipal Mestra Fininha}

Em todo programa educacional a ser implantado percebe-se, no seu decorrer, diversos desafios, mas também aparecem as possibilidades que reforçam a vontade de querer persistir. Como desafios, os sujeitos elencaram as seguintes situações:

C1 - O maior desafio que encontramos é o espaço físico, é o pior que temos aqui na escola. Em segundo lugar são aqueles pais que não veem a Educação de Tempo Integral como uma maneira de estar recebendo um apoio na escola, eles pensam que tirar a criança da casa nesse horário não pode, é muito tempo para a criança ficar fora de casa. E o acolhimento dos 
professores? No início tivemos uma barreira muito grande, eles não entendiam de maneira alguma, achavam que o programa vinha para atrapalhar, que a criança cansava muito. Não foi realizado nenhum trabalho com os pais e com a comunidade no sentido de que eles entendessem mais sobre a ETI e se sentissem parte integrante.

O sentimento de pertença é relevante na medida em que proporciona um envolvimento consciente e responsável no ambiente em que está inserido, isso não foi o que a EMMF fez, iniciaram as atividades mesmo sem a participação da comunidade envolvida nas decisões. O mesmo foi feito com os professores regentes, a SME apresentou a ETI já estruturada, sem dar oportunidade de análise dos seus aspectos constitutivos. Isso acabou gerando uma insatisfação, como pode ser visto no relato dado por $\mathrm{C} 1$, quando afirma que "o programa vinha para atrapalhar". Nem os professores nem os pais foram envolvidos na implantação da ETI na EMMF.

Em outro contexto, pode-se verificar que um desafio foi a aceitação, o acolhimento da ETI pelos professores da escola. Eles acreditavam que, se a criança voltasse para escola e/ou permanecesse nela, não iria estudar, fazer suas tarefas e, com isso, iria manter um baixo rendimento nas disciplinas. Verificou-se que a decisão em implantar a ETI não foi devidamente discutida nem planejada. Esse é um dos grandes desafios presentes em praticamente todas as políticas públicas educacionais do nosso país.

Com relação aos desafios a gestora afirmou que "Faltou estrutura, começamos um projeto sem ter estruturado a escola, faltou um ambiente para poder receber esse projeto. Então, nós fomos adaptando, nós ainda temos uma vantagem que nosso espaço é grande, então através de cada recurso que nós recebemos, juntamos, fizemos galpões, criamos uma estrutura que ficou bacana para recebermos essas oficinas, mas ainda nos falta a questão do vestiário, do lado da higiene. Nós precisamos trabalhar, ter uma política pública, ou uma interferência de equipar as escolas estruturalmente, o que falta é estrutura física para poder receber os meninos e talvez conseguir ampliar isso para a comunidade, para mãe ou pai.

Verificou-se, que os desafios são muitos, desde a implantação da política da ETI e em todo o seu desenvolvimento. A gestora tomou para si o compromisso de melhorar a infraestrutura da escola, no intuito de buscar o envolvimento dos pais na escola.

Moll (2009) entende que a extensão do tempo-quantidade deve ser acompanhada por uma intensidade do tempo-qualidade nas atividades que constituem a jornada ampliada na instituição escolar. Essa extensão tempo-qualidade deve envolver os professores da unidade de ensino, pais e comunidade, no sentido de não protelar esforços para o alcance de uma ETI de qualidade.

Os oficineiros apresentaram desafios como o aspecto financiamento, tendo em vista que necessitam de materiais para ministrarem suas atividades, o contexto social no entorno 
da escola, a agressividade dos alunos e o currículo que tinham que aplicar. Segundo eles, os alunos não estavam acostumados com o diálogo e queriam resolver tudo na agressão, e o currículo que utilizavam não apresentava aquilo que, de fato, atendesse ao que os alunos precisavam, era algo predeterminado pelos coordenadores. Por isso, muitas vezes, não o aplicavam e trabalhavam o que atendia melhor aos interesses e anseios do alunado.

Mediante a autonomia pedagógica prevista no ordenamento legal, as escolas conseguem elaborar seus próprios currículos escolares, sem ferir o que determina a LDBEN n. ${ }^{\circ}$ 9.394/96. Quem lida diariamente com a ETI tem que ser criativo e persistente para conseguir manter o aluno no programa. Isso pode ser percebido no momento em que oficineiros e professores executavam suas atividades com os alunos, pois se desdobravam na realização das atividades. Os desafios descritos fizeram entender que o que permeia a ETI não é somente o conteúdo e os conhecimentos específicos para a preparação para o trabalho, mas também valores e cidadania.

No que tange às possibilidades a ETI chegou até o município com o ambicioso objetivo de transformar a Educação Básica. Apesar de enfrentarem grandes desafios, os envolvidos na ETI da EMMF apontaram como possibilidades de mudanças a socialização dos alunos, a valorização das classes menos favorecidas pela sociedade, a ajuda às famílias no intuito de orientar os seus filhos retirando-os das ruas e da vulnerabilidade.

Os pesquisados apontaram, ainda, possibilidades que poderão ajudar na elaboração de uma proposta pedagógica mais voltada para a realidade da ETI, na qual a comunidade e os demais professores pudessem se envolver mais nas atividades e a própria SME fosse mais parceira das unidades de ensino, prestigiando mais as atividades desenvolvidas na escola e no seu entorno, bem como proporcionando maiores capacitações em que todos das escolas, e não somente os envolvidos, pudessem compreender melhor o programa Mais Educação/Escola de Tempo Integral.

Para os participantes os projetos poderiam dar continuidade sem as interrupções por questões políticas, o IDEB poderia atingir um índice maior, a frequência das crianças poderia ser maior, a comunidade poderia fazer valer seus espaços para aprimoramento do conhecimento ao se envolver mais nas atividades, as condições materiais poderiam ser ofertadas constantemente, a infraestrutura seria adequada, a capacitação dos envolvidos aconteceria, periodicamente, para todos. Todos esses aspectos são possibilidades da ETI. 


\section{Considerações Finais}

Neste trabalho se propôs analisar o funcionamento da ETI numa unidade de ensino municipal de Montes Claros-MG, os desafios encontrados e as possibilidades apresentadas pelos envolvidos para a consecução dos seus objetivos.

$\mathrm{Na}$ categoria funcionamento e infraestrutura, os sujeitos apresentaram como ocorreu a implantação da ETI na unidade de ensino, bem como delinearam a necessidade de adequação do espaço utilizado para a realização das atividades. Em acordo com o que prevê esses documentos, afirma-se que a EMMF precisa se adequar para continuar recebendo alunos na ETI. Os espaços são inadequados, salas improvisadas e faltam materiais para a realização das atividades. Cumpre as diretrizes no que diz respeito ao funcionamento, fazendo que com as crianças permaneçam na unidade de ensino por sete horas e meia. Porém, esse funcionamento é questionável.

Com relação à interlocução escola-comunidade, as discrepâncias foram observáveis quando todos os envolvidos na pesquisa alegam que somente convidam os pais e comunidade para visitarem a escola em momentos de eventos culturais e esportivos. Afirmam ainda que, para garantir cerca de sessenta por cento de presença, é necessário oferecer lanches para os pais. Em nenhum momento expressa que fez parcerias com instituição, ONGs, clubes ou mesmo postos de saúde para que, a partir delas, a unidade saia dos seus muros e atinja o papel de interagir com a comunidade. Acredita-se que esse distanciamento se deu pelo fato de a unidade de ensino se encontrar em comunidade de alta periculosidade e os envolvidos terem receio de se locomoverem nesse ambiente. Mas a intenção da ETI é fazer com que a escola possa ser vista pela comunidade como aquela que ajuda os moradores e valoriza seus espaços, transformando a comunidade uma parceira da escola.

Percebeu-se também, no momento das observações e das análises dos relatos, que os envolvidos desconhecem que tipo de parcerias podem firmar e as razões para tal. Eles preferem ficar na unidade de ensino desenvolvendo suas atividades sem inovação, sem enfrentamento dos obstáculos que se encontram na comunidade, o que é agravante para um programa em que o trabalho com as interações é necessário e faz com que se busque diminuir os riscos e a vulnerabilidade em que as crianças estão inseridas.

Tudo isso posto nos remete ao conhecimento dos envolvidos sobre a ETI e EI. Nos questionamentos feitos com essa intenção, todos, até mesmo o gestor da unidade de ensino, demonstraram não ter conhecimento suficiente sobre o programa com que lidam. Executam as ações tendo como base o senso comum e, quando tentam conceituar, diferenciar e falar sobre os objetivos e pressupostos da ETI, não os apresentam com segurança. 
No que se refere à categoria práticas pedagógicas, os oficineiros, estagiários e professores ainda desenvolvem práticas autoritárias, em que são decididas as atividades a partir de uma padronização. Poucas atividades propiciam a análise da realidade e o querer buscar melhoria da comunidade em que estão inseridos. Os conteúdos estudados são os mesmos do ensino regular, com exceção do tempo utilizado para ministrá-lo.

A prática pedagógica voltada para aulas diferenciadas é o que foi relatado, mas, ao observar e discutir com os próprios docentes, chegou-se à conclusão de que não existe inovação nas aulas, pois realizam oficinas e seguem um mesmo padrão todos os dias. Essa metodologia é mecânica e não propicia a inovação.

Analisou-se também os impactos da implantação da ETI na EMMF, na comunidade e nos envolvidos. Pelos relatos evidenciou-se mais desafios, como, por exemplo, o não comprometimento dos pais com a educação dos filhos, a falta de material pedagógico, o despreparo dos envolvidos na ETI, a infraestrutura inadequada, eles não foram capazes de chegar à conclusão sobre o que realmente impactava a comunidade com a implantação da ETI. Somente um oficineiro afirmou que houve uma modificação para melhor no comportamento de alguns alunos agitados e agressivos. Eles acreditam que, após estarem participando das oficinas de Karatê e Judô, os alunos demonstram mais tranquilidade na resolução dos conflitos, tanto dentro como fora da escola. Este foi o grande impacto na vida da comunidade.

Esses desafios não amedrontaram os educadores. Em seus relatos, eles deixaram claro que abraçaram a proposta da EI e ETI e a tornaram realidade nas escolas municipais em Montes Claros-MG. Mesmo com tanta dificuldade, ousaram e se empenharam em busca de uma educação de qualidade.

Moll (2009), ao transitar pelos conceitos de educação integral, apontou o seu significado político e social. Apresentou em suas discussões como fazer acontecer a ETI, buscando nas parcerias uma cumplicidade e favorecendo, através da educação, um repensar sobre a condição social das crianças e adolescentes. Em se tratando de ETI, sempre é aconselhável buscar o conhecimento além daquele que está posto. Percebemos que lidar com a condição social das pessoas e muitas vezes com seus sonhos leva-nos a apostar numa educação de qualidade e na diminuição das desigualdades sociais.

A Educação de Tempo Integral continua como uma política pública capaz de redimensionar a educação no país. Porém, deve-se entender o lugar de onde se fala, para quem se fala e as razões pelas quais se implanta essas polícias públicas de educação. Intentar em manter as escolas com projetos que busquem aumentar as oportunidades das crianças na sociedade perpassa por profissionais que se comprometam em fazer uma educação diferente, 
modificando também suas práticas. Desmistificar, deixar de lado seus tabus, quebrar paradigmas em busca de um novo rumo na educação é entendido como um objetivo da EI.

É na perspectiva da qualidade social, cultural e científica que se terá a Educação de Tempo Integral como aquela que perpassa os muros da escola para envolver a comunidade em busca de possibilitar maiores e melhores oportunidades educacionais e, desse modo, possa contribuir para amenizar a histórica desigualdade social que assola o Brasil.

\section{Referências:}

BARDIN, Laurence. Análise de conteúdo. Tradução de Luís Antero Neto e Augusto Pinheiro, Lisboa: Edições 70, 2010.

BRASIL. Instituto Nacional de Estudos e Pesquisas Educacionais Anísio Teixeira. Censo da educação básica: 2012 - resumo técnico. Brasília, 2013.

BRASIL. Decreto n. ${ }^{\mathbf{7}} \mathbf{7 . 0 8 3}$, de 27 de janeiro de 2010. Dispõe sobre o Programa Mais Educação. Brasília: MEC, 2010.

BRASIL. Ministério da Educação. Documento Referência: Conferência Nacional de Educação. Brasília: MEC, 2009.

BRASIL. Educação integral: texto referência para o debate nacional. Brasília: MEC, 2009.

BRASIL. Portaria Normativa Interministerial $n^{\circ} 17$ de 24 de abril de 2007. Dispõe sobre o Programa Mais Educação. Diário Oficial da União, 26 abr. 2007.

BRASIL. Lei n. ${ }^{\circ}$ 9.394, de 20 de dezembro de 1996. Lei de Diretrizes e Bases da Educação Nacional. Diário Oficial da União, Brasília, DF, 23 dez. 1996. https://doi.org/10.5380/jpe.v 10i20.49964

BRASIL. Constituição (1988). Constituição da República Federativa do Brasil. Brasília: Senado Federal subsecretaria de Edições Técnicas. 2006. https://doi.org/10.11606/d.2.2010.tde-13122010-160747

CAVAliERE, Ana Maria. Escolas de tempo versus alunos em tempo integral. Em Aberto, Brasília, v.22, n. 80, p.51-61, abr., 2009.

COELHO, Lígia Martha Coimbra da Costa (org.) Educação Integral em tempo integral: estudos e experiências em processo. Petrópolis, RJ: DP et alii, Rio de Janeiro: FAPERJ, 2009. https://doi.org/10.24824/978854441844.4

DEWEY, John. Democracia e Educação. Tradução de Godofredo Rangel e Anísio Teixeira. 4. ed. São Paulo: Editora Nacional, 1979.

GADOTTI, Moacir. Educação Integral no Brasil: inovações em processo. São Paulo: Editora e Livraria Instituto Paulo Freire, 2009. 
MAURÍCIO, L. V. Escrita, representações e pressupostos da escola pública de horário integral. Em Aberto, v. 22, n. 80, p.15-31, 2009.

MINAS GERAIS, Montes Claros. Diretrizes Operacionais para as Escolas de Tempo Integral de Montes Claros. Secretaria Municipal de Educação, 2016. Mimeo. https://doi.org/10.17655/9788567211169

MIZUKAMI, Maria da Graça N. et al. Escola e aprendizagem da docência: processo de investigação e formação. São Carlos: EdUSCar, 2003.

MOLL, Jaqueline. Histórias de vida, histórias de escolas: elementos para uma pedagogia da cidade. Petrópolis: Vozes, 2009.

MONTES CLAROS. Relatório Final 2013-2014. Escola Municipal Mestra Fininha. Montes Claros-MG. Mimeo.

MONTES CLAROS. Diretrizes Operacionais para as escolas municipais de educação de Tempo Integral. Secretaria Municipal de Educação de Montes Claros-MG, 2016. Mimeo. https://doi.org/10.14393/ufu.te.2019.925

MONTES Claros. Projeto Político Pedagógico da Escola de Tempo Integral, Montes ClarosMG, 2013. Mimeo.

MORAES, José Damiro de. Educação integral: uma recuperação do conceito. In: COELHO, Lígia Martha Coimbra da Costa (org.) Educação Integral em tempo integral: estudos e experiências em processo. Petrópolis, RJ: DP et alii, Rio de Janeiro: FAPERJ, 2009. https://doi.org/10.24824/978854441844.4

NÓvOA, Antônio. Profissão professor. Lisboa: Porto Editora, 1995.

ANTUNES, Ângela. PADILHA, Paulo Roberto. Educação cidadã, educação integral: fundamentos e práticas. São Paulo: Editora e Livraria Instituto Paulo Freire, 2010.

PARO, Vitor Henrique. Educação integral em tempo integral: uma concepção de educação para a modernidade. In: COELHO, Lígia Martha Coimbra da Costa (org.) Educação Integral em tempo integral: estudos e experiências. Petrópolis, RJ: DP et alii; Rio de Janeiro: FAPERJ, 2009. https://doi.org/10.11606/d.48.2014.tde-17122014-103428

SOUZA, Ediléia Alves Mendes. Prática Pedagógica de qualidade na Educação Infantil em Escola de Tempo Integral: visão de professores. $147 \mathrm{f}$. Dissertação de

Mestrado. Universidade de Brasília: Faculdade de Educação, 2012. https://doi.org/10.11606/d.47.2000.tde-01112001-151523

TEIXEIRA, Anísio. Educação não é privilégio. 6ª ed. Rio de Janeiro: UFRJ, 1999. 